\title{
ROBERT MUSIL FRENTE A ERNST MACH
}

\author{
Mauricio Jalón \\ Universidad de Valladolid (GIR Rodrigo Zamorano)
}

\begin{abstract}
RESUMEN
Sobre las teorías de Mach (TD de R. Musil) rebate que la representación científica tienda a construir un claro y completo inventario de hechos. Pues Mach se ve obligado a presuponer relaciones constantes en la naturaleza; pero esta regularidad de los fenómenos implica que la ley es algo más que cierto «cuadro», que las meras dependencias que defiende están en un segundo plano y que una relación teórica en física es mucho más que una relación de orden. Su concepción de la economía científica como «adaptación natural» significa un monismo biológico opuesto a las dualidades propias de un empirista.
\end{abstract}

PALABRAS CLAVE: Mach. Representación científica. Inventario. Economía. Regularidad.

\section{ROBERT MUSIL VERSUS ERNST MACH}

\begin{abstract}
On Mach's Theories (DT of R. Musil) rejects that the scientific representation tends to build a clear and complete inventory of facts. Mach finds himself obliged to presuppose constant relationships in nature; but this regularity of phenomena implies that the law is something more than a «table», that its mere dependencies are pushed into the background, and that a theoretical relationship in Physics is much more than an order relationship. His conception of scientific economy as a «natural adaptation» implies a biological monism opposed to the characteristic dualities of an empiricist.
\end{abstract}

KEY WORDS: Mach. Scientific representation. Inventory. Economy. Regularity.

La producción científica e intelectual de Ernst Mach (1838-1916) tuvo lugar en el último tercio del siglo XIX y al inicio de la centuria siguiente. Por esos años surgieron visiones inéditas sobre el calor, la naturaleza de la luz y la propagación de campos electromagnéticos que facilitaron el remate del programa canónico de la física. También han de contarse la difusión amplia del evolucionismo, del vitalismo organicista, del artificio químico-orgánico o de la rica y obsesiva reestructuración matemática: las nuevas concepciones geométricas, aritméticas o algebraicas formales facilitaron un replanteamiento lógico — general o histórico — de buena parte de sus cimientos. Todos estos 
desarrollos pusieron en cuestión la jerarquía de las ciencias ilustrada, esa gradación clasicista de lo simple a lo complejo que fue delineada con un plan muy general y que todavía afectó a sus coetáneos, pues siguieron elaborándose clasificaciones de las ciencias siguiendo ese proceso demasiado rectilíneo.

Ahora bien, el nombre de Mach ha sido asociado a la reacción frente a cualquier dogma conceptual o, en otras palabras, a cierto escepticismo contemporáneo que facilita un tiempo de espera - término usado por él y por otros- durante el cual nos interrogamos sobre las condiciones de validez de cada aserción que se nos propone. Tales cambios en la ciencia, tan difundidos y vertiginosos, como decía Boltzmann, fueron un caldo de cultivo para el escepticismo machiano, junto a la crisis de los conceptos de la física clásica (la noción de fuerza fue repasada a fondo), a la aparición de las ideas de campo o de energía y, desde luego, a la diversidad de teorías en conflicto: realismo y fenomenismo, causalidad y vínculo funcional, atomismo y energetismo. Esta rotación de teorías parecía convertir el mundo científico en un lugar de opiniones en perpetua mudanza, lo que propiciaba un nuevo pirronismo pero también - a la muerte de Mach - su correspondiente réplica constructiva; ya en el siglo XVII había sucedido, de otro modo, con Mersenne ${ }^{1}$ y su optimista Verité des sciences (1625).

La crisis finisecular, que afectó a los restantes dominios de la cultura, llegó al menos hasta la Primera Guerra Mundial, cuando empezaron a asentarse las nuevas teorías que removerían la ciencia física. La situación era aún muy vacilante, se avizoraban los rumbos que ésta iba a adoptar pronto, pero en estas condiciones de incertidumbre no es de extrañar que científicos tan dispares como Einstein, Bohr, Planck o Heisenberg defendieran sin ambages que los problemas centrales de la física teórica se hallaban fundidos con los epistemológicos, como sucedió en los momentos inaugurales de la ciencia moderna. El término 'epistemología', se supone que introducido hacia 1850 por James Ferrier, vino a convertirse por entonces, a principios del siglo XX, en un vocablo de uso corriente, pues sucede que la precisión del sentido que había que adoptar para conseguir un verdadero cambio conceptual tuvo un matiz netamente epistémico.

Ernst Mach, afincado desde 1895 en la ciudad donde fue estudiante, Viena, escribió casi tres mil páginas y tuvo especial audiencia en el período de

1 Que acompaña al nacimiento de la ciencia moderna: PoPKIN, R.H. (1983), La historia del escepticismo desde Erasmo hasta Spinoza, México, FCE, cap. VII. 
«entresiglos» ${ }^{2}$. Alabado o discutido entre 1903 y 1908, la serie de comentarios y críticas al científico dio pie a un cuerpo de publicaciones que deberían considerarse mejor para ver cómo se acrisoló conceptualmente la física contemporánea. Sin embargo, a medida que avanzaba el siglo XX su figura fue difuminándose; y sólo en las últimas décadas de la centuria volvió a recuperarse, aquí y allá, su obra, con intenciones críticas o hagiográficas ${ }^{3}$. Esta revisión, interesante más bien desde una perspectiva histórica, hoy está algo estancada.

Un evento entre las discusiones germinales sobre Mach lo constituyó una singular tesis doctoral, hoy centenaria, de Robert Musil (1880-1942). La redactó antes de consagrarse de pleno a la escritura, iniciada en 1906 con Las tribulaciones del joven Törless. Musil, nacido en Klagenfurt, se formó inicialmente como técnico en academias militares austriacas, e hizo estudios de ingeniería que finalizó en 1901; para cimentar esa orientación, desde 1904 profundizó sus conocimientos en lógica y psicología experimental durante seis semestres en Berlín; allí leerá su tesis, en 1908, que atañe, según su certificado, a la filosofía, la física y la matemática ${ }^{4}$. En efecto, Sobre las teorías de Mach es un documento teórico-científico donde hizo un balance implacable y muy bien trabado sobre la ya concluida obra del físico. Resulta un dato significativo de la recuperación machiana el que fuese publicado, al fin, en Alemania (1980); o que apareciera en Milán poco antes (1973), y algo después en París (1985)5.

2 Por ejemplo: LuCKA, E. (1903), Das Erkenntnisproblem und Mach's Analyse der Empfindungen, Kantstudien, 8, 396-447; Hönigswald, R. (1903), Zur Kritik des Mach'schen Philosophie, Berlín, C. A. Schwetschke und Sohn (que cita Mach al final de su Análisis de las sensaciones, or. 1885); KLEINPETER, H. (1905), Die Erkenntnistheorie der Naturforschung der Gegenwart, Leipzig, Barth; CARUS, P. (1906), Professor Mach's Philosophy, The Monist, 16, 331-356, Chicago; REY, A. (1907), La Theórie de la physique chez les physiciens contemporains, París, F. Alcan; Schulz, R. (1907), Die Mach'sche Erkenntnistheorie. Y otros cuatro más en 1908, contando a Lenin, Materialismo y empirocriticismo.

3 Destacó el estudio de Blackmore, J.T. (1972), E. Mach: His Work, Life, and Influen$c e$, Berkeley, Univ. of California. Y hubo unos lustros de interés por su obra, cf. el trabajo internacional coordinado por Prosser, V. y Folta, J. (1991), E. Mach and the Development of Physics, Praga, Univerzita Karlova; y Holton, G. (1992), Ernst Mach and the Fortunes of Positivism in America, Isis, 83 (1), 27-60; cierto reflujo posterior no impide trabajos amplios como el de BANKS, E.C. (2003), E. Mach's World Elements. A Study in Natural Philosophy, Dordrecht, Kluwer.

4 Berghahn, W. (1972), Robert Musil, Reinbek bei Hamburg, Rowohlt, pp. 35-58.

5 MusiL, R. (1980), Beitrag zur Beurteilung der Lehren Machs, Reinbek, Rowohlt, con una nota de A. Frisé, su gran editor; es la primera edición de su tesis, pues no está en MusIL, R. (1978), Gesammelte Werke $=G W$, Reinbek, Rowohlt; hicimos una rápida comunicación 
Musil fue un estudioso plural, además de un enorme literato, resultando ser uno de los intelectuales europeos más agudos de la primera mitad del siglo XX; en él se aunaron rigor y conocimiento enciclopédico en grado sumo $^{6}$. Su compromiso ético, además, le llevó a exiliarse y morir pobremente en 1942. Estar al lado de las letras no le impidió ser un conocedor de la física por sus dobles estudios, y llegó a ser uno de los escasos escritores-físicos, como señaló un testigo de su madurez en los años treinta, Elias Canetti, en el capítulo «Musil» del tercer tomo de su autobiografía, El juego de ojos. Lo fue en muy alto grado, remacha éste, y continuó siéndolo en toda su obra, ya que se había integrado en la sustancia misma, «en la carne y en la sangre», de su pensamiento. Poseía, además, una mente analítica inhabitualmente severa y transparente, que rechazaba cualquier mentalidad híbrida o dudosa y que elegía el camino de la precisión, aunque desdeñase cualquier argumento simplificador ${ }^{7}$. Precisamente, la concisión y la densidad, tan ejemplares, del texto musiliano contrastan con el carácter impreciso o errabundo de los escritos de Mach, y ayuda a ver cómo en éstos se trasparentan muchos aspectos anticuados del razonar decimonónico.

Ahora bien, pese a la ingenuidad de sus formulaciones (sus propuestas están más bien hilvanadas) y la precariedad de su teorización, Mach, de hecho, constituyó un polo para la reflexión científica de los primeros años del siglo $\mathrm{XX}$, ya que puso a la luz muchas dudas acerca de los principios de la física, de su organización misma y de sus posibilidades en varias de sus obras. Sin embargo, parece hoy como si esta revisión machiana fuese un «compás de espera» para la física-matemática, antes de que otros diesen un paso decisivo en la dirección actual, más bien ajena a la que él propugnaba. Pero la combinación de análisis lógico de la ciencia y de historia - la denominada posición histórico-crítica machiana-, sirvió de extraño diapasón para las sucesivas batallas contra el residual dogmatismo clasicista y el rígido determinismo cientificista de su centuria. Pues, más que el monismo de Mach, a veces pintoresco, o su forma de meditar sobre la organización de las percepciones,

sobre esa obra en un congreso de Historia de la Física: Mahón, 1987. La versión, anunciada para 2007 (Sobre las teorías de Mach, México, Sexto Piso), se ha estancado.

6 Cf. Frisé, A. (1980), Unvollendet-unvollendbar?, Merkur, 390, 1099-1115; MAGRIS, C. (1999), Dietro quest'infinito: R. Musil, L'anello di Clarisse, Turín, Einaudi, pp. 212-255.

7 Serres, M. (1992), Exacto y humano, El paso del Noroeste, Madrid, Debate, II. 2. Y el notable: Assoun, P.-L. (1985), Musil, lecteur d'Ernst Mach. En Musil, R., Pour une évaluation des doctrines de Mach, París, PUF, pp. 5-48. 
quizá fue su recuperación del escepticismo —o, mejor, de lo que hay en él de lucha contra todo apriorismo - lo que pudo atraer, entonces, a pensadores de diversos ámbitos. Los ataques continuados a la «metafísica» — blanco, a menudo muy vaporoso, de tantos científicos y filósofos- son, en el fondo, descalificaciones tajantes de cualquier exceso causal o racionalista.

La alternativa de Mach era partir de una especie de constelación fenoméni$c a$, algo indefinida, como caso particular del impresionismo que invadió al pensamiento vienés; pues era el correlato de un yo irremediablemente perdido, atomizado, según la idea machiana, lo que conduce a suponer una especial sensibilidad, flotante y sin sujeto ${ }^{8}$. Con todo, significó cierto avance en esa búsqueda de la complejidad y la pluralidad metodológicas que fructificarían más tarde gracias también, desde luego, a nuevos estímulos. Otras fórmulas resumen las preocupaciones del momento, y pueden entenderse como ideas curativas, paralelas, de los males de la investigación. Pues si Wittgenstein, que ha sido opuesto a Mach y emparentado con Musil, va a escribir más tarde (en las Investigaciones filosóficas) que la filosofía expone a secas, sin concluir nada firme, pero dispone de diferentes e imprescindibles terapias ${ }^{9}$, Musil propugnaba en su combate teórico un desmenuzamiento de la verdad en determinadas verdades, apelando al uso de la fragmentación y la ironía como una forma concluyente de limpieza intelectual ${ }^{10}$.

Pues bien, la perspectiva científica de Musil nos sirve todavía hoy para analizar al Mach tardío, para acercarnos a su modo de discurrir errátil y algo informal. Por esas mismas fechas, Musil estaba leyendo a vitalistas como Dilthey o Simmel y también a Cassirer (que derruía con armas neokantianas casi estructuralistas las premisas del siglo XIX). Con ese doble frente, reflexionaba sobre el conflicto fructífero entre los métodos racional y no racional ${ }^{11}$. Sin

8 Johnston, W.M. (2009), El genio austrohúngaro: historia social e intelectual, 18481938, Oviedo, KRK, cap. 13; KobRY, Y. (1986), E. Mach et le «moi insaissisable». En ClaIR, J. (coord.), Vienne, 1880-1938, París, Pompidou, pp. 124-129.

9 Cf. Wallner, F. (1986), Le sens peut-il naître du non sens? Musil, Mach et Wittgenstein. En Cometti, J.P. (coord.), Robert Musil. Colloque 1985, París, Fondation Royaumont, pp. 133-145; Gargani, A. (1982), Musil, Wittgenstein et l'esprit de la modernité, Sud (Hors série Musil), 32-47.

10 Musil, R. (1978a), Was arbeiten Sie?, GW, VII, p. 941. El ejemplo explícito se ve en Musil, R. (2004), Diarios, Barcelona, DeBolsillo, con referencias constantes al conocimiento y a la ciencia; cf. MAGRIS, C. (2002), Dietro le parole, Milán, Garzanti, pp. 366-370.

11 Musil, R. (1978b), Skizze der Erkenntnis des Dichters, GW, VIII, pp. 1025-1030 (o Ensayos y conferencias, Madrid, Visor, 1992, pp. 64-68). Cf. BOUVERESSE, J. (1978), La science sourit dans sa barbe, $L^{\prime}$ Arc, $74,8-31$. 
olvidar a Nietzsche, que le inquietaba, Musil defendía con entusiasmo que el pensamiento más osado de entonces se encontraba en la ciencia exacta y que, como una especie de higiene mental, se debería leer, en este orden, a Mach, Lorentz, Einstein y Minkowski, a Couturat, Russell y Peano ${ }^{12}$. El futuro gran escritor se sentía a gusto entre hombres de ciencia - y no como diletante, como muestra su tesis-, hasta el punto de que si no se considera esa faceta de su personalidad, aún poco analizada, el análisis de la cultura científica vienesa de su época resulta algo mermado.

Todo ello muestra el singular interés - histórico y sobre todo conceptualque merece su enjuiciamiento de Sobre las teorías de Mach. Una indagación de estilo envolvente que, tras efectuar un rápido balance de las premisas metodológicas de ese conocido físico, recorre en espiral sus razonamientos principales -recurriendo siempre a las fuentes directas-, para llegar al siguiente dictamen, basado en una crítica definida explícitamente como inmanente: que los escritos machianos, pese a sus cualidades pragmáticas, presentan tantos paralogismos o, al menos, tantas contradicciones, que su edificio argumental en conjunto se tambalea, siendo imposible atribuirles, por ende, una «importancia decisiva» ${ }^{13}$.

Como Musil sabe establecer eficazmente, las propuestas de Mach suponen una visión de la ciencia como tarea descriptiva y no explicativa; significan un rechazo de la causalidad y de cualquier tipo de sustancialismo, así como una defensa de un modelo de descripción efectuado mediante el estricto estudio relacional entre componentes adecuados. Representan, además, la afirmación de que las leyes, conceptos y teorías de la ciencia han de percibirse como vehículos simplificadores del estudio de la naturaleza; y ello supone, finalmente, un intento de resolver la conexión entre los mundos físico y psíquico gracias a la categoría instintiva de «adecuación» y el análisis de las correspondencias entre sensaciones (que, para Mach, equivalen a relaciones entre «elementos», como en el territorio de la física). Estos serían, a juicio de $\mathrm{Mu}-$ sil, los rasgos del intento machiano por lograr una recta y simplificada administración de las categorías científicas.

Con su filtro implacable, el gran escritor irá localizando, casi sin respiro, la forma en que Mach plantea el conocimiento científico y, en particular, en su concepción de la física como un fenómeno de adaptación regido por el principio de economía mental. A continuación, meditará sobre su modo de entender el papel del juego conceptual o el de la teoría en esa rama científica tan

12 MusiL, R. (1978c), Profils eines Programms, GW, VIII, p. 1318 (o Ensayos, pp. 323-329).

13 MusiL (1980), pp. 22 y 133-134. 
activa a comienzos del siglo XX. Y concluirá examinando la crítica machiana de la noción de causalidad, y su sustitución por un concepto de función apoyado en la «teoría de los elementos» que se corresponde con su sensualismo.

Desde el primer momento, Musil constata las filiaciones - tanto la sensualista (Condillac) como la positivista (Comte) — propias de su razonamiento. Filiaciones a las que deben unirse el escepticismo de Hume, el experimentalismo de J. Stuart Mill y el naturalismo evolutivo de Darwin y Spencer, cuyo punto de partida no sería "esencialmente distinto» del machiano. Y es que tales antecesores son explícitamente reconocidos por $\mathrm{Mach}^{14}$; incluso su Conocimiento y error, de 1905, está dedicado al escéptico escocés. Todo él parece remitir a una «Ilustración» difusa pero omnipresente, o, mejor, a herramientas mentales que arrancan de las Luces: el pensamiento francés del siglo XVIII es una plataforma del ideario de Comte, y de Mill, cuyo asociacionismo psicológico y empirismo le avecinan además a Hume.

Por lo demás, en Austria — país de fuerte, y autóctona, tradición logicista-, era común la aplicación de la razón ilustrada a cualquier parcela intelectual. Asimismo, aunque el racionalismo de Comte y su fe absoluta en el carácter invariante de las leyes naturales le alejen de Mach, éste, sin embargo, dice apoyarse únicamente en los fenómenos, pretende articular una psicología científica y propone, de hecho, una teoría válida para todos los campos de estudio. Más que atribuir cierto positivismo encubierto a quienes dialogaron y se enfrentaron con él, como Planck o Einstein ${ }^{15}$, parece necesario destacar cómo Mach está, de antemano, inmerso en principios positivistas acendrados.

Pero no es este el debate que conviene seguir, pues Musil se atiene en todo momento a la trayectoria mental machiana, y sigue el curso de cada uno de sus razonamientos; incluso está interesado por ver cómo el positivismo de Mach en apariencia es consecuente con sus investigaciones físicas concretas: según afirmaba éste, todas sus convicciones provenían de sus directos y continuos trabajos en física. De todos modos, Musil se ve obligado a «inventar» la sistematización de la que está desprovista la doctrina de Mach, que, a su juicio, no consiste más que en un conjunto de aforismos diseminados ${ }^{16}$. Esta

14 MACH, E. (1987a), Análisis de las sensaciones, Barcelona, Alta Fulla, pp. 42, 65, 71-74 y 83; MACH, E. (1986), Principles of the Theory of Heat. Historically and Critically Elucidated, Dordrecht, Reidel, pp. 339, 356 y 391-393 (or. 1896).

15 Véase, por ejemplo, Feyerabend, P.K. (1984), Mach's Theory of Research and its Relation to Einstein, Stud. Hist. Phil. Sci., 15 (1), 1-22. Cf. FeYerabend, P.K. (1982), La ciencia en una sociedad libre, Madrid, Siglo XXI, pp. 232-242.

16 MusiL (1980), pp. 21-22. 
búsqueda sistemática se concreta en una gradual ampliación de las cuestiones que aborda; de modo que, en cada nuevo tramo, va integrando las cuestiones precedentes, hasta ensamblarlas y componer una suerte de agregado teórico con cierta armazón y con un núcleo caracterizador de Mach que, eso sí, hace más fácil la impugnación musiliana.

$\mathrm{Al}$ considerar una naturaleza tan maleable o penetrable para el observador, Mach fuerza un paralelismo entre los territorios externo y psíquico; afirma de un modo tajante que las «unidades que llamamos «yo» las vemos incesantemente nacer y morir», como las exteriores, pues. Para él existe una unión necesaria de lo sensible y lo racional, gracias a un monismo en donde el todo y la parte se unen natural e inextricablemente; lo físico y lo psicológicosensitivo pueden adecuarse de forma tal que entre los mundos exterior e interior no ha de existir abismo alguno, como es propio de una tradición empirista moderna ${ }^{17}$. Es verdad que un estudioso de la cultura como Schorske señaló, ya hace tiempo, cómo esa permeabilidad entre el yo y el mundo era una característica de todo el fin-de-siècle vienés ${ }^{18}$. Pero Mach arranca, en particular, de la convicción de que sólo el conocimiento de los hechos tiene valor para el físico: es la única meta del científico, asegura, hasta el extremo de que aquello que no aparte de ellos podría interpretarse como un mero rodeo intelectual. Y este punto de partida, más bien vago, aparece reforzado por la idea de que el interés del científico debe concebirse como un tipo de «interés biológico indirecto». Incluso, Mach apuntó, en Conocimiento y error, que las leyes de la naturaleza podrían entenderse como limitaciones o restricciones mediante las cuales, y bajo la dirección de la experiencia, ordenamos nuestra espera de los fenómenos. Por ello, sugería sustituir el término «descripción» (Beschreibung) de Kichhoff, por el giro «restricción de la espera» (Einschränkung der Erwartung), para resaltar ese ritmo biológico que alcanzaría a las leyes naturales ${ }^{19}$. Una «paciencia ordenada» posibilitaría a su juicio captarlas.

$\mathrm{Si}$, según Planck, ello suponía una visión afectada por fabulaciones antropomórficas $^{20}$, de forma convergente Musil afirmaba que su acentuar el carác-

17 MACH (1987a), cap. IV (El punto de vista esencial en el análisis de los sentidos), y la frase en p. 314. Véase Verley, X. (1998), Mach, un physicien philosophe, París, PUF, pp. 14, 8283 y 122.

18 Schorske, C. (1981), Viena Fin-de-Siècle, Barcelona, G. Gili, p. 356.

19 Cf. MACH, E. (1968), Erkenntnis und Irrtum, Darmstadt, Wissenschaftliche Buchgesellschaft, pp. 449-453.

20 Véase el texto de Planck, M. (1970). En Toulmin, S. (coord.), Physical Reality, Nueva York, Harper \& Row, pp. 1-52. 
ter práctico de la ciencia sería, más bien, consecuencia de la concepción instintiva - decimonónica- que Mach defendía. Él extendió las categorías darwinistas al devenir del pensamiento ${ }^{21}$ : como cualquier actividad humana, y al igual que sucede con los organismos más elementales, la ley de autoconservación regiría también la ciencia ${ }^{22}$. Así, Mach entendió que la tarea de las ciencias era sólo un aspecto de la misión histórica, más amplia, que está latente en la evolución de las especies. Pero traducir los problemas de la ciencia a un lenguaje organicista, dice Toulmin, no arroja, en definitiva, luz alguna sobre los cambios intelectuales que se producen en ella ${ }^{23}$, más aún, identificar criterios de selección intelectuales con los económico-operativos, orgánicos, es confuso y peligroso ideológicamente.

En la interpretación machiana, el proceso investigador ha de verse sometido siempre a un desarrollo estrictamente determinado, de forma tal que la ciencia ha de observarse desde las perspectivas de la continuidad - es decir, de la permanencia y la diferenciación suficiente-, y de la economía ${ }^{24}$. Ambos criterios se unen en el buen gobierno del pensamiento científico, de modo que el método por el que este saber se constituye siga un proceso gradual de reajustes que tienda a economizar todos los recursos mentales en una investigación concreta. Como Mach pretende ahorrar experiencias considerando la figuración o copia adecuada de hechos mediante el pensamiento —así, en La mecánica (1903) - , le interesa, no la teoría, sino la problemática que afecta a éste: la adaptación de los pensamientos a los hechos, la similitud, el ajuste de diversos pensamientos entre sí, la economía del pensamiento y la experimentación mental ${ }^{25}$. Tras ese control, los conceptos, leyes y teorías irían adecuándose a ese ideal de simplificación eficaz. Todos los recursos investigadores, por tanto, deberán subordinarse a semejante premisa ahorrativa, un tanto genérica, de la mente.

Para Musil, que califica dicho enfoque de indiferente y escéptico, ese camino no conduce a una verdadera busca de los fundamentos del conocimiento. Propicia, por su volatilidad, afirmaciones tan aisladoras como que las teo-

21 Véase, por ejemplo, MACH (1986), caps. XXIII (Evolución de la ciencia) y XXV (Transformación y adaptación en el pensamiento científico); y МАCH (1968), pp. 108-111.

22 Cf. MusiL (1980), pp. 23-25.

23 Toulmin, S. (1977), La comprensión humana, I, Madrid, Alianza, cap. 5, pp. 324-325.

24 MACH (1986), cap. XXVI (Economía de la ciencia). Véase sobre su génesis, BANKS, E.C. (2003), The Philosophical Roots of Ernst Mach's Economy of Thought, Synthese, 139, 2353. La crítica, en MusiL (1980), pp. 27-31.

25 Mach, E. (1987b), La mécanique. Exposé historique et critique de son développement, París, Gabay, cap. IV, 4; y la síntesis en p. 462. 
rías de la transmisión del calor o de la naturaleza de la electricidad sólo encuentran una aparente justificación en el azar histórico que supuso su descubrimiento. Aun así, cuando todo parece obtenido mediante observaciones fortuitas, Mach niega ser el portavoz de una posición nihilista. Y a esta paradoja se suma el hecho de que ciertas hipótesis de la Mecánica que él combate son casos de manifiesta continuidad en el desarrollo de esta rama, lo que sin duda contraría sus premisas.

Por lo demás, el mismo principio de continuidad es tan vasto que, como llega a reconocer $\mathrm{Mach}^{26}$, puede aplicarse a todo tipo de pensamiento, y afecta tanto al falso como al verdadero. Y es que las relaciones entre la exactitud de un razonamiento y su carácter continuo o discontinuo, así como su valor económico o no económico, no pueden reducirse a un único criterio ecuménico, y tampoco se entrecruzan entre sí de forma indiferente o casual, sino que se implican por diversos caminos, localizados, específicos y ramificados, según recalca Musil.

Como Mach está defendiendo el carácter de adaptación, que es propio de la ciencia en general, cabe ampliar el campo de la discusión. Para la argumentación inductiva más típica, el combate entre la verdad y el error se realiza a través de procesos, dependientes de la base empírica, que implican un suceder de aproximaciones asintóticas que, en cada momento, puedan dar muestras de que la descripción se adecua, en grado suficiente, al estadio concreto de cierta investigación. Más ceñidamente, Mach subraya que una descripción puede calificarse de adaptada cuando es capaz de reproducir y prefigurar hechos, de modo que las hipótesis se ajusten a ellos. Lo cual no sólo coincide con las ideas inductivas antes expuestas, sino que, sobre todo, muestra que el criterio de economía en el pensamiento - aunque siga teniendo un valor general innegable-, es algo secundario en el proceso indagador ${ }^{27}$.

Por añadidura, dada la imagen machiana de una representación aleatoria y condensada del acaecer de los fenómenos, los conceptos físicos carecerían de autonomía y de cualquier valor explicativo. Si, a la manera de Hume, la causalidad debe concebirse como un añadido mental, otro tanto sucede, por ejemplo, con las nociones de masa o de energía, de inercia o de temperatura. Asimismo, entonces, cada malla conceptual y cada sistema conjunto se ven reducidos a una posición subalterna, dice Musil. Tanto la diversidad de teorías opuestas, en su época, como la recepción, aunque simplificadora, de las

26 Cf. МАCH (1968), pp. 108-125.

27 Musil (1980), pp. 38-42, y también pp. 53-54. 
ideas de Maxwell o su contemporáneo Hertz sobre el valor representativo de las hipótesis, condujeron a Mach a tales aseveraciones. Además, cuando gira en torno al carácter descriptivo de la ciencia, empieza por distinguir dos vías de pormenorización de los sucesos, una directa y otra indirecta (indirekte Beschreibung), asignando a la primera la exclusividad de la aprehensión conceptual y acercando la segunda al tratamiento de los hechos. Esta casuística provoca una escisión de ambos mundos, pues - sin menoscabo del valor de la experiencia - un «hecho» no es algo aislado, no pertenece tan sólo al ámbito de lo perceptible, y además pasa por alto que, como Musil sentencia, toda clase de descripción tiene inexcusablemente una naturaleza conceptual ${ }^{28}$.

En general, el empirismo se define en verdad en un dualismo - la dualidad empírica se establece entre las causas de las percepciones y las causas de las relaciones, como escribió Deleuze-, lo cual hace cuartear el proyecto monista machiano. En el modelo empirista originario (Hume), enseguida se aprecia que, por un lado, el espíritu carece de las notas características de un sujeto (no es algo activo sino que se ve activado, «sujetado») y, por otro, que la totalidad se entiende como una vasta colección. La razón se concibe como una «especie de sentimiento»y, en consecuencia, la única especulación aceptada es la teoría de la práctica —en la que se combinan experiencia y hábito- - dado que, para el empirismo, no existe subjetividad teórica alguna sino sólo un positivismo del entendimiento. La ciencia, así, se ve obligada a volcarse en el estudio de la naturaleza humana; todas las ciencias se relacionarían por necesidad con ésta, parte activable del conjunto. De ahí que tal escuela, en contra de lo que parece a primera vista, se caracterice por su desaforada creación de conceptos ${ }^{29}$; y ello también repercute en el rebuscamiento de la terminología de Mach.

Aproximándose ya a su tiempo, el positivismo mantiene, no sin paradoja, la bipartición del mundo establecida por la metafísica (la esencia y el fenómeno, lo necesario y lo contingente), aunque altere la jerarquía de cada una de las partes, según el primer Habermas. Es una corriente que desdeña la tradición filosófica hasta el punto de que sólo se sirve de la reflexión para la «autoeliminación de la reflexión sobre el sujeto cognoscente». Y, sobre todo, proyecta la física y la psicología sobre un único plano, para obtener «un sistema de refe-

28 Para todo el párrafo, cf. MusiL (1980), pp. 42-47 y 49-54; cf. pp. 61-66.

29 Según Deleuze, G. (1981), Empirismo y subjetividad, Barcelona, Gedisa, 1981, pp. 1723, 28 y 120-121; cf. DeleuZE, G. (1968), Différence et répétition, París, PUF, p. 3. Pues nada tiene de negación de los conceptos, sino su proliferación, con el matematismo abstracto consiguiente. 
rencia en el que ambas sean compatibles»», a fin de evitar la solución de continuidad entre diversos hechos: sólo habría «fenómenos». El razonamiento científico, entonces, aparece como el únicamente posible; y la ciencia, como lugar seguro, queda preservada de toda crítica ajena a ella. Pero, así, al no abordarse reflexivamente los conceptos metafísicos, «éstos conservan su poder sustancial incluso contra su enemigo»: lo que desea ser el positivismo machiano ${ }^{30}$. Aquí nacen sus círculos viciosos, que Musil pone en evidencia precisamente.

Pero no sólo critica este presunto desmontaje de estructuras teóricas. También, ya en particular, Musil examina la depuración machiana de las raíces mismas del pensamiento científico. Así, a fin de negar la noción fundamental de causalidad, Mach critica el análisis desarrollado por Helmholtz, en su estudio sobre la conservación de la fuerza, señalando que la pretendida causa por él introducida no es sino el complemento ficticio de un complejo de hechos: para Mach, tal «complejo» positivo es lo único que produce el pretendido efecto dinámico que estudia. Y de ello quiere servirse para borrar, según afirma, toda huella sustancialista en las nociones científicas y, a cambio, exaltar el concepto de función como el más certero vehículo de la física moderna.

Ahora bien, esta defensa machiana de la representación funcional, su uso mismo del concepto de «representación» tan discutido por los físicos de entonces - significativamente, Musil elige, como Hertz, Darstellung y no ese Vorstellung que originó tantas confusiones, también en Mach ${ }^{31}$ - y su lucha contra el sustancialismo son, una vez más, excesivamente holgados. Pues así como es indiscutible el papel de los hechos en la construcción de los conceptos $^{32}$, también lo es que este proceso - y se ha planteado desde Newton hasta Fechner o Kirchhoff y Hertz- sólo debe concebirse dentro de lo que vino a denominarse «universo funcional» $»^{33}$. Por otra parte, las formas primitivas, ingenuas y un tanto sustanciales que adoptaban las nacientes nociones científicas han ido quedando relegadas, o han desaparecido sin más, en el curso de la historia. Decía Bachelard que la ciencia está en el orden de «un pensamiento repensado y de una experiencia reencuadrada», cuando recordaba que el propio Mach reconocía esa consolidación retroactiva que todos los conceptos

30 Habermas, J. (1982), Conocimiento e interés, Madrid, Taurus, pp. 85-95.

31 Cf. Toulmin (1977), pp. 200-204. Mach afirma que Hertz, tan valioso, difiere en su perspectiva teórica por ese motivo: MACH (1987b), pp. 250-256.

32 MACH (1986), cap. XXIX (El concepto); МACH (1968), pp. 126-143. Véase MACH (1987a), p. 282-283: «Una buena parte de la adaptación conceptual se realiza inconsciente e involuntariamente bajo la dirección de los hechos sensibles», y de ahí nace, mediante nuevas experiencias correctoras, la «adaptación conceptual intencionada, o sea, la investigación».

33 Musil (1980), pp. 66-82. 
han de experimentar necesariamente ${ }^{34}$; de ahí que no quepa hablar ya de un «primitivismo» científico a finales del siglo XIX, cuando confluían grandes creadores de la matemática o de la física (así, un Poincaré).

Musil no se deja engañar por estas aspiraciones, tan amplias. Según le critica, reiteradamente Mach se limitaría a acentuar lo estrictamente fisico de su punto de vista; lo que no implica, dice el primero, el hallazgo de esa vía «antimetafísica» que busca con denuedo. Pues Mach establece, por un lado, que los conceptos son superfluos, si nos basamos en los hechos (en el fondo, la imagen científica del mundo está perfectamente terminada ya para él); por otro, que las ecuaciones funcionales son las únicas aseveraciones legítimas de la física, y que la naturalidad de las relaciones entre unos caracteres y otros, así definidas, obedece a una mera necesidad lógica ${ }^{35}$. Y lo decisivo es que su defensa del concepto de función (Funktion), en último término, supone resaltar que las dependencias exclusivamente se captan en la esfera de la lógica y que ésta es - en vez de la causalidad, la compleja «razón»— la que, en verdad, fundamenta el conocimiento. Su apoyo en el fisicalismo, aunque sea alguna vez indirecto, y su rotundo enclaustramiento en el espacio lógico son el resultado fatal de haber aceptado, sin condiciones, el juego de la dualidad entre términos y relaciones. En suma, Mach se encierra en la cárcel de las tautologías al constituirse en abanderado de una necesidad lógica ${ }^{36}$ que pretende ser tan exclusiva y purificadora como arbitraria.

Surgen además otros problemas, que también analiza Musil. Los elementos científicos invocados por Mach no pertenecen ni al interior ni al exterior, según intenta decirnos. Pero tienden a ser absorbidos por la esfera de lo psíquico o de lo físico en cuanto entran en contacto con otros elementos. Por una parte, los conceptos, en principio carentes de fundamento, cobran una decisiva relevancia en ciertas discusiones de Mach. Por otra parte, le resulta asimismo difícil evadir esa invariante que es la sustancia, pues siempre acaba remitiéndose carnosamente a nuestras reacciones sensoriales ante los hechos. Más aún, la investigación al final desembocaría, «dando un rodeo, en lo que el conocimiento sensible ofrece inmediatamente ${ }^{37}$. La constancia de estas

34 BACHELARD, G. (1975), La actividad racionalista en la fisica contemporánea, Buenos Aires, Siglo Veinte, p. 32; cf. BACHELARD, G. (1973), El compromiso racionalista, Buenos Aires, Siglo XXI, pp. 158-159.

35 MusiL (1980), pp. 82-85.

36 MACH (1986), cap. XXXI (esp. pp. 393-395). Cf. MUSIL (1980), pp. 89-91.

37 MACH (1987a), p. 287. Antes señala que «los hechos son ampliados y enriquecidos, y últimamente simplificados por el tratamiento conceptual». Es una especie de estética de la ciencia: MACH (1987b), p. 78. 
reacciones implica una permanencia física, de tal modo que nos remite, de nuevo, a ese factor concreto y unificador natural: en definitiva, la esencia de las ecuaciones formulables radica en la reconstitución de $\operatorname{los}$ hechos ${ }^{38}$, reencontrándonos con la invariancia fisicalista que se ha resaltado ya.

Tras el repaso de la lucha neobaconiana de Mach contra ciertos ídolos especialmente contra los del «teatro», los doctrinales, los de los falsos métodos-, Musil critica otros rasgos, que también nos parecen característicos del baconismo ilustrado y, por tanto, no serían incorporables sin más al programa científico del siglo XX. Pues es en verdad sintomático que Mach equipare las leyes naturales a simples tablas de hechos aislados, a reglas que permiten deducir y producir hechos (leyendo y encadenando tales datos), o a abreviaturas especialmente útiles para la memoria. En tales condiciones, una ley sería un extraño, por arbitrario, mediador entre los fenómenos; sería una especie de regulador cuantitativo de las representaciones sensoriales. El enlace funcional es, entonces, una mera dependencia calculatoria y sirve para averiguar lo característico cuantitativamente sin más ${ }^{39}$.

Pues la idea de repertorio era fundamental para Mach: el ideal al que la representación científica tiende, según asevera, es construir un «completo y claro inventario de hechos de cierto dominio», que esté preparado de un modo simple y económico, además de manejable ${ }^{40}$. Pues si el mundo se percibe como una colección, la ciencia aparece convertida en una mera caja de instrumentos, una retícula de artificios. Y tras semejante dispositivo tabulador se esconde su oposición a la idea de necesidad natural. Un «cuadro de datos» se revelaría como la astucia de la experiencia, como la disposición más discontinua y objetiva de los hechos. Pero esta premisa machiana, escribe finalmente Musil, supone la culminación de sus contradicciones. Pues, en los momentos críticos, Mach se ve obligado a presuponer relaciones constantes en la naturaleza; y esta regularidad de los fenómenos implica, indudablemente, que la ley es algo más que cierto cuadro, que sus dependencias calculadoras están en un segundo plano y que una relación teórica es mucho más que una relación de orden ${ }^{41}$.

Como se ve, Musil se ve obligado, una y otra vez, a elevarse hasta un plano reflexivo partiendo de los análisis físicos e histórico-críticos realizados por

38 MUSIL (1980), pp. 85-87.

39 Musil (1980), pp. 98-106; dice literalmente: «Mach betrachtet die Naturgesetze als blosse Tabellen einzelner Tatsachen...», p. 98.

40 MACH (1986), p. 415, frase que subraya el autor.

41 Musil (1980), pp. 110-134. 
Mach. Por su parte, Boltzmann recurría con suma naturalidad a la filosofía más consistente. Pero Mach negaba a menudo ser un filósofo ${ }^{42}, \mathrm{y}$, aunque en efecto sus escritos pertenecen más a la metodología práctica de la ciencia, resulta irónico constatar que la mayoría de las discusiones que suscita requieren un claro tratamiento reflexivo. Incluso cabe decir que su trayectoria podría entenderse como la adopción de una posición prekantiana muy terminante; y este radicalismo habría facilitado el trabajo posterior de postkantianos consecuentes y renovadores: Cassirer ${ }^{43} \mathrm{y}$, siguiéndole, Toulmin contraponen Mach a Hertz y Planck, precisamente desde esta perspectiva ${ }^{44}$.

El esfuerzo de Mach por atenerse a los hechos resultaba un atractivo ejercicio para el Musil científico e intelectual, pues es propio de los momentos de crisis volverse hacia los primeros pasos de la investigación, como si fuese necesario bucear en lo impreciso para conseguir, luego, una mayor precisión. Musil, al denunciar la mayor de las paradojas machianas - el rechazo y la aceptación simultánea de la necesidad natural-, coincide con Planck, que polemizó con Mach por su imagen arbitraria del universo físico. Y también coincidía con él al defender la riqueza y el peso de la trama teórica ${ }^{45}$ : las tareas de la ciencia son intelectuales, insistía Planck; es decir, que la renovación periódica de las exigencias explicativas es lo que determina la evolución de la física. En 1910, también Cassirer, en su Concepto de sustancia, concepto de función - que tuvo eco entre los científicos-, recordaba, polemizando con Mach, que un inventario es un esfuerzo insuficiente y que describir un suceso natural supone explicarlo en todos los sentidos, de modo que cualquier empresa presuntamente sensualista tiene que acabar recurriendo a las ideas de las que reniega, incluyendo la ley de constancia ${ }^{46}$.

42 Lo señala en varios de sus escritos — así Musil (1987a), p. 43-, y dice acogerse gustosamente al pensamiento del vulgo. Pero se reconoce en una tendencia filosófica verdadera consistente en reunir la ciencia en un sistema único: MACH (1987b), p. 3.

43 Véase CASsirer, E. (1976), Filosofia de las formas simbólicas, III, México, FCE, pp. 38-45; y CASSIRER, E. (1979), El problema del conocimiento en la filosofia y en la ciencia modernas, IV, México, FCE, pp. 114-134. Véase SEIDENGART, J. (1990), Théorie de la connaissance et épistémologie de la physique selon Cassirer. En SEIDENGART, J. (coord.), Ernst Cassirer, de Marbourg à New-York, París, Cerf, pp. 159-176.

44 Cf. JaniK, A. y Toulmin, S. (1974), La Viena de Wittgenstein, Madrid, Taurus, pp. 171-180.

45 Cf. el clásico Bouvier, R. (1923), La pensée d'Ernst Mach, París, Vélin D’Or, p. 326.

46 CAssirer, E. (1977), Substance et fonction, París, Minuit, pp. 298-300, 346-348. Sobre esta Substanzbefriff, en Musil (1980), pp. 77-79. Publicado en 1906, casi al tiempo que esos libros, el empirista DuHEM, P. (2003), La teoría fisica, su objeto y su estructura, Barcelona, Herder, caps. IV y V, razona con equilibrio, y se sitúa más allá de Mach. 
La posición machiana supone un desplazamiento del terreno sistemático al dominio histórico. Esta incursión en la historia científica, de corte positivista, que discute la aparición de los conceptos y defiende a ultranza la clasificación de los fenómenos, tiene como contrapartida su desconfianza hacia la matemática. Mach tendía, sobre todo, a prevenirnos del posible abuso - por místico y esotérico, por maníaco hasta el absurdo ${ }^{47}$ - del proceder matemático. En esto también aparece como un ferviente empirista.

Precisamente, en un repaso de los métodos de la física teórica, Boltzmann distinguía entre un fenomenismo matemático y el fenomenismo general y asistemático de Mach, que renunciaba a toda captación unitaria de la naturaleza. Y concluía que tal atención a los fenómenos sólo podría vanagloriarse de su propia cautela ${ }^{48}$. Recordando, con Goethe, que la experiencia es, en el fondo, sólo la mitad de la experiencia, afirmaba que, si sobrepasamos lo dado con valentía (podría decirse, mediante la forma matemática), lograremos mejores visiones globales y encontraremos incluso hechos raros o inauditos, aunque aumente la posibilidad de error, que deberá atajarse.

Al comenzar el siglo XX, la matemática experimentaba una fuerte reestructuración - con la consiguiente metamorfosis de la idea de mathesis universalis - y se producía un debate lógico-epistemológico centrado en Leibniz y protagonizado por Russell, Couturat y Cassirer; al que cabe, incluso, añadir las Investigaciones lógicas de Husserl. Mach, perteneciente a otra generación, se mantuvo de espaldas a esta corriente; pero es que siempre su opinión sobre Leibniz fue tan desdeñosa como la de la Ilustración anglófila. Y precisamente el concepto de función, el mecanismo de la significación o la importancia de la forma lógica son claros temas leibnizianos, cuya estela en la historia del pensamiento hoy tiene un alcance muy superior al escepticismo machiano, siempre provisional.

Como se ha visto, Musil estaba atento a los cambios producidos en ambos terrenos. Es indudable que cualquier remodelación de la matemática no afecta de inmediato a otras ciencias. También lo es que las relaciones entre matemáticos y físicos no siempre han sido excelentes. Pero, precisamente, el dogmatismo de la ciencia exacta del clasicismo había sido bastante erradicado, de modo que sería posible llevar a la física ese «sistematismo coherente» propugnado por Cassirer, construido merced a un bastidor racional-matemático suficientemente flexible.

47 MACH (1987b), p. 80.

48 Boltzmann, L. (1974), Theoretical Physics and Philosophical Problems, Dordrecht, Reidel, pp. 95-96; decía en 1899: «En efecto, cuando considero todos esos desarrollos y revoluciones me siento como un monumento de la antigua memoria científica», p. 82. 
La evolución de Einstein, a este respecto - su inicial prejuicio ante la matemática y el posterior reconocimiento de su vigor crucial-, es paralela, según Holton, a su tránsito de una primera afinidad con Mach a su definitiva identificación con Planck. En 1918, Einstein comparaba el ideal de Planck con la armonía leibniziana, encontrando aquí la raíz de la controversia que éste y Mach mantuvieron, en los años del trabajo de Musil ${ }^{49}$. La defensa musiliana del valor del método es correlativa de la reafirmación einsteniana, algo posterior, de la libre construcción de conceptos, del papel rector del lenguaje matemático, y del carácter especulativo inherente a cualquier teoría ${ }^{50}$. En 1922, para resaltar los elementos «temáticos» frente a los fenoménicos, Einstein rechazaba que la ciencia sólo constase de datos y de relaciones entre ellos, pues si Mach conseguía construir un catálogo, nunca conseguiría dar con un buen sistema ${ }^{51}$.

Por añadidura, dada la reducción machiana de todo hecho a meros fenómenos, a la discutible inconstancia de la naturaleza le corresponde una no menos dudosa inconstancia subjetiva. Pues, como dice Cassirer, la idea de adaptación progresiva exige la constancia de cada entidad en lo posible. La lucha de Mach contra el sustancialismo y el animismo, su eficaz escepticismo inicial, resultó finalmente infructuosa. Por un lado, su repudio del atomismo es una mera proyección de las limitaciones de su sensualismo, pues simplifica el sentido que el atomismo tiene, incluso desde la Antigüedad. Por otro, su concepción pictográfica le valdrá ser tachado de metafísico por Planck, Duhem o Poincaré. Los círculos viciosos resaltados por Musil en su Beitrag zur Beurteilung der Lehren Machs son capaces de dar cuenta de las dos caras del mismo problema ${ }^{52}$.

Un paso más, antes de concluir. Y es que su original análisis tiene otro paralelo aún en el diagnóstico ofrecido desde otra posición, no ajena a la ciencia

49 Einstein, A. (1918), Principios de investigación. En Einstein, A. (1981), Mis ideas y opiniones, Barcelona, Tusquets, pp. 199-202. Hoy tal cambio de perspectiva es un tópico de su biografía, cf. BRIAN, D. (2005), Einstein, Madrid, Acento, pp. 105-109; IsAACSON, W. (2008), Einstein, Barcelona, Debate, pp. 195-196, 386-387, 501.

50 Einstein, A. (1933), Sobre el método de la física teórica. En EINSTEIN (1981), pp. 242247. Véase el colectivo coordinado por SchILPP, P.A. (1970), Albert Einstein: Philosopherscientist, La Salle, Illinois, Open Court, parte I; y HolTon, G. (1982), Ensayos sobre el pensamiento científico en la época de Einstein, Madrid, Alianza, cap. 4, pp. 164-203.

51 Holton (1982), pp. 183, 187 y 194.

52 CASSirer (1977), p. 299; y CASSIRER (1979), p. 118. Véase MACH (1986), p. 389, cuando afirmaba que «la filosofía atómica moderna es un intento de hacer de la noción de sustancia, en su forma más ingenua y cruda, el concepto fundamental de la física». 
y heredera directa de Stumpf, que fue profesor de filosofía de Husserl y también de Musil ${ }^{53}$. Pues Husserl, en 1900, aceptaba la idea de «función económica» de Mach como un punto de vista sobre todo teleológico, valioso para la biología y de cierta utilidad en la práctica de la ciencia. Pero le reprochaba varios fallos epistemológicas: su confusión de lo «efectivamente dado» con lo «lógicamente ideal», su nivelación de los pensamientos natural y lógico, su presentación de la actividad científica como una mera prolongación de la casi ciega actividad natural, y, por último, su creencia en la primacía del proceso de representaciones contingentes sobre las necesarias. La visión machiana de la ciencia como fenómeno bio-psicológico, de hecho, le alejaría de plano de una concepción epistemológica de ésta como unidad ideal de verdad objetiva ${ }^{54}$.

La mirada de Husserl, que parte de los fundamentos de la matemática, y la de Musil, que arranca de las nociones cruciales de la física, pueden complementarse para valorar críticamente la curiosa posición de Mach en la historia de la ciencia. Pues aún tienen interés las cuestiones que suscita, si bien hay que localizarlas en sus antecedentes y en su tiempo, para buscar respuestas con ayuda de coetáneos cuyo esfuerzo intelectual fue más fértil. Por otro lado, la obra musiliana en su integridad, tan concreta y tan abstracta como es, atestigua una singularidad personal en la que la rareza de su emplazamiento se une con su aptitud para evocar precisamente la generalidad desde la minuciosa descripción de lo particular: esta tesis doctoral, científica, suya de 1908 lo pone de manifiesto; también lo expondrá su gran proyecto literario, El hombre sin atributos, que planteaba como cierto relato social e histórico de una Viena en crisis mediante ciertas «experimentaciones intelectuales» ${ }^{55}$. La obra quedó significativamente inconclusa en un mundo austriaco ya desgarrado.

Fecha de recepción: 30 de mayo de 2008

Fecha de aceptación: 12 de enero de 2009

53 También el maestro de C. Stumpf y de E. Husserl, fallecido en 1917, dejó un manuscrito crítico con las posiciones machianas; hoy, accesible: BRENTANO. F. (1988), Über Ernst Mach's «Erkenntnis und Irrtum», Ámsterdam, Rodolpi.

54 Husserl, E. (1985), El principio de la economía del pensamiento y la lógica, Investigaciones lógicas, Madrid, Alianza, Prolegómenos, cap. 9, esp. pp. 172-177. Mach le respondió brevemente en 1903, señalando que lo suyo eran esbozos sobre el desarrollo del conocimiento, enraizados en la vida misma de la humanidad: МACH (1987b), pp. 462-464.

55 Cf. Peyret, J.F. (1975), Musil et les contradictions de la modernité, Critique, 339$340,846-863$. 